International Journal of Applied Dental Sciences 2021; 7(3): 178-182

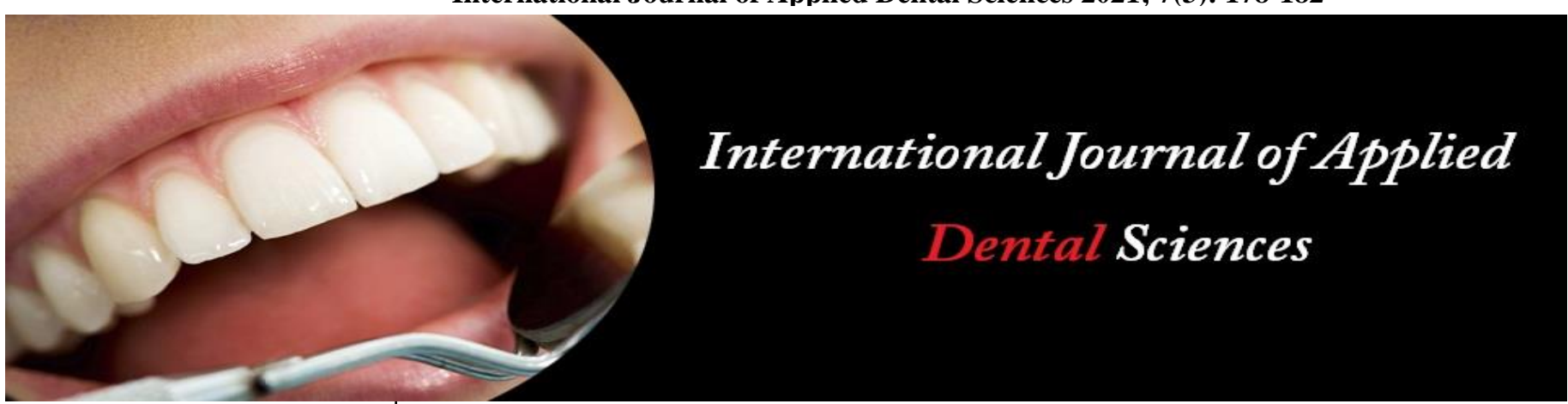

ISSN Print: 2394-7489

ISSN Online: 2394-7497

IJADS 2021; 7(3): 178-182

(C) 2021 IJADS

www.oraljournal.com

Received: 22-05-2021

Accepted: 24-06-2021

Dr. Johara Maria Cruz

Professor, Department of

Prosthodontics, Sathyabama

Dental College and Hospital

(Deemed University), Jeppiar

Nagar, Shollinganallur, Chennai,

Tamil Nadu, India

Dr. Keerthi Narayan V

Senior Lecturer, Department of Oral Pathology and

Microbiology, Thai Moogambigai

Dental College and Hospital,

Chennai, Tamil Nadu, India
Corresponding Author:

Dr. Keerthi Narayan V

Senior Lecturer, Department of

Oral Pathology and

Microbiology, Thai Moogambigai

Dental College and Hospital,

Chennai, Tamil Nadu, India

\section{Effect of tooth loss on rugae pattern in complete and partially edentulous individual: A forensic perspective}

\section{Dr. Johara Maria Cruz and Dr. Keerthi Narayan V}

DOI: $\underline{\text { https://doi.org/10.22271/oral.2021.v7.i3c.1298 }}$

\section{Abstract}

Background: Preservation of palatal rugae plays an important role in prosthetic rehabilitation and in forensic identification when the individual has no teeth either completely or partially owing to its resistance and stability. However recent studies have shown substantial rugae pattern changes are caused by tooth loss of prolonged duration.

Aim: The present study was carried to compare and evaluate the effect of tooth loss on rugae pattern among completely and partially edentulous maxillary arch individuals as a reliable personal identification tool.

Methodology: A total of 50 participants were divided into two groups comprising of 25 completely edentulous (Group A) and 25 partially edentulous (Group B) individuals. Impressions, maxillary casts were made and the number, type of rugae patterns were recorded using graphite pencil and tracing paper every 3 month over a period of 1year based on Martins dos Santos classification system.

Results: More complex patterns (line, curve, circle, bifurcated, sinnous) are observed in Group B with significant differences between the mean values of line, bifurcated and circle pattern when compared to Group A. Simultaneously mean differences in sinnous pattern (Group A) and Sinnous, Line pattern (Group B) within the group were also seen over a period of 1 year.

Conclusion: The present study thus showed significant differences in the rugae pattern between both the groups and greater changes with complex patterns were observed in partially edentulous group when compared with the complete edentulous group.

Keywords: line rugae pattern, partially edentulous, personal identification, soft tissue evidence, tooth loss

\section{Introduction}

Human identification plays an important role in the field of forensic investigation for recognition of victim/suspects at the crime scene, soldiers, missing persons; for medico-legal authorizations; personal identification following road traffic accidents, terrorist assaults, and natural or any mass disaster situations such as floods, earthquakes, industrial or fire accidents, and landslides [1]. This identification process can be broadly categorized as primary identification methods that includes Fingerprint analysis, comparative dental soft tissue and hard tissue investigation and DNA examination from skin, blood and hair samples followed by secondary identification methods such as personal descriptions like jewelry, birthmarks, tattoo, implant prosthesis, clothing and medical records pertaining to any specific deformities in an individual ${ }^{[2]}$. Comparative dental evidence examination remains one of the pillars in identification of remnants following post-mortem alterations, excessive tissue injury/loss of tissue or in absence/lack of primary evidences like fingerprints and DNA samples ${ }^{[3]}$. Forensic dentistry or Forensic odontology is a branch of dental science that deals particularly with proper handling and examination of all available dental evidences to aid in establishment of the individuality of a person either alive or dead specifically in deceased conditions where the human remains are severely decomposed beyond recognition following mass disasters and accidents ${ }^{[4]}$.

Oral cavity encompasses both hard and soft tissue components. The hard tissue component predominantly tooth along with its supporting structures like alveolar bone are used in documentation of dental features such as number of teeth, restorations, prosthesis, dental 
caries, malocclusion, tooth anomalies and also aid in construction of facial profile for recognition of an individual by comparing the available ante-mortem (AM) and postmortem records (PM) ${ }^{[5]}$. The chief shortcoming of using dental identification method arises in circumstances when the suspected victim has no teeth either completely or partially in which the personal identification methods are primarily restricted to use of soft tissue such as lip print, palatal rugae and so on. Palatal rugae are asymmetric anatomical folds or ridges present in the anterior region of the palatal mucosa composed of dense fibrous tissue outspreading on either sides of the mid-palatine raphe just behind the incisive papillae that facilitates transportation of food, swallowing, suckling, taste perceptions as well as speech process ${ }^{[6]}$. Rugae pattern, well protected by lips, cheek, tongue, buccal pad of fat and teeth in certain conditions such as burnt bodies in incident of fire or higher temperatures or where bodies have decomposed severely and encountered high impact trauma can be an effective personal identification tool ${ }^{[7]}$.

Preservation of rugae plays an important role in prosthetic rehabilitation especially among completely edentulous individuals as it acts as the stress bearing area that prevents displacement of the denture anteriorly ${ }^{[8]}$, guides in setting the maxillary teeth at the anterior region and provides indirect retention in denture extension cases ${ }^{[9]}$. Nevertheless rugae pattern are least susceptible to external environment changes and are unique to every individual often considered as a consistent relevant marker of forensic importance ${ }^{[10]}$. Over the years studies have shown severe finger sucking in infancy, persistent orthodontic pressure and prolonged absence of tooth/tooth loss may contribute to substantial changes in rugae pattern that may impact largely on the identification process ${ }^{[11,12]}$. Hence the present study was carried out to compare and evaluate the effect of tooth loss on rugae pattern in completely edentulous maxillary arch with that of partially edentulous maxillary arch individuals as a reliable personal identification tool.

\section{Materials and Methods}

\subsection{Selection of study participants}

The present study was carried out in the Department of Prosthodontics, Crown and bridge and Implantology, Sathyabama Dental College and Hospital, Chennai. The study comprised of 50 participants distributed into two groups. Group A comprised of 25 individuals with completely edentulous maxillary arch and Group B comprised of 25 individuals with partially edentulous maxillary arch categorized based on several inclusion and exclusion criteria independent of age, gender, diet and other oral related habits. For completely edentulous maxillary arch, patients undergoing full mouth and/or upper arch rehabilitation with mobile teeth or periodontally compromised teeth indicated for extraction, multiple teeth missing over a prolonged period of time were included in the study. For partially edentulous maxillary arch criteria includes patients with grossly decayed teeth, mobile teeth or periodontally compromised teeth indicated for extraction on the anterior region and multiple teeth missing over a prolonged period of time not indicated for full mouth rehabilitation till premolars were selected. Individuals with palatal abnormalities like asymmetrical palate, lesions affecting mucosal or bony structures, patients on orthodontic treatment, history of palatal surgeries, missing teeth other than anterior region till premolars were excluded from the study. After the institutional ethical committee (IEC) clearance and a written consent from patient, a detailed history of all the patients was recorded.

\subsection{Methodology}

Maxillary arch impressions for both groups were made using alginate (an irreversible hydrocolloid material) and a cast was poured with die stone (type $\mathrm{V}$ gypsum). The rugae patterns were marked with graphite pencil on all the impression cast (Figure 1, 2) and mapped using tracing paper. These identified patterns were then categorized based on Martins dos Santos classification system which offered a simple, feasible and preferred classification based on rugae location (Figure 3). All the patients were recalled and same procedures were repeated every 3 month over a period of 1year. New impressions and cast were made and traced during every visit and compared with the previous visit cast (Figure 4, 5). All the observations were recorded and tabulated for statistical evaluation.

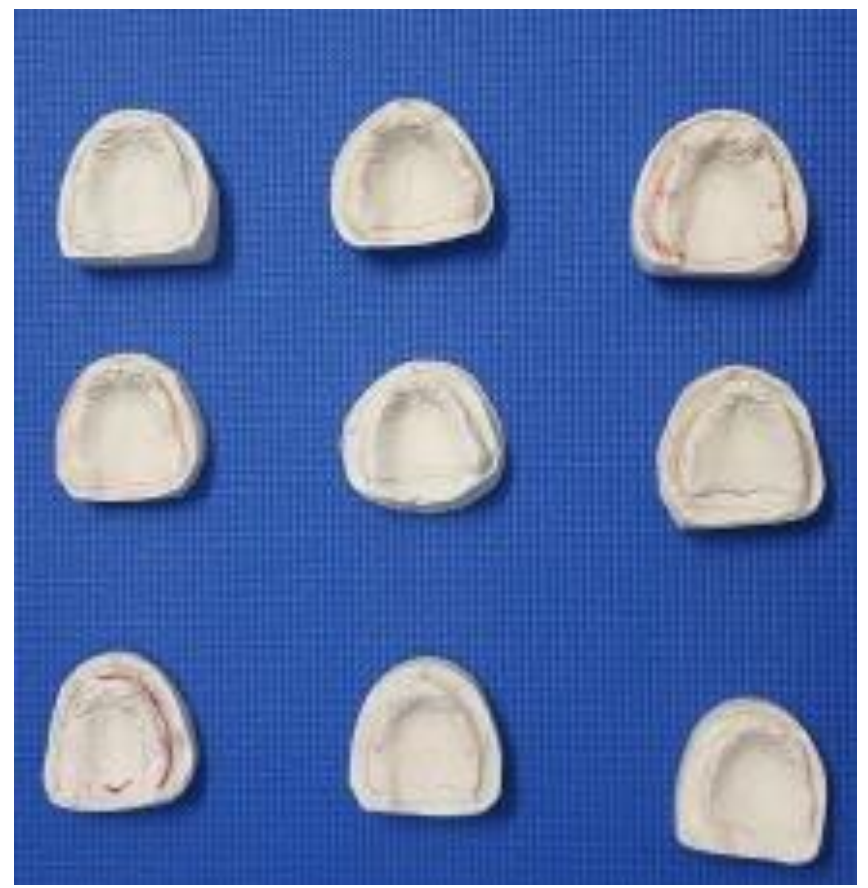

Fig 1: Image showing the tracing of different rugae pattern on the completely edentulous maxillary cast

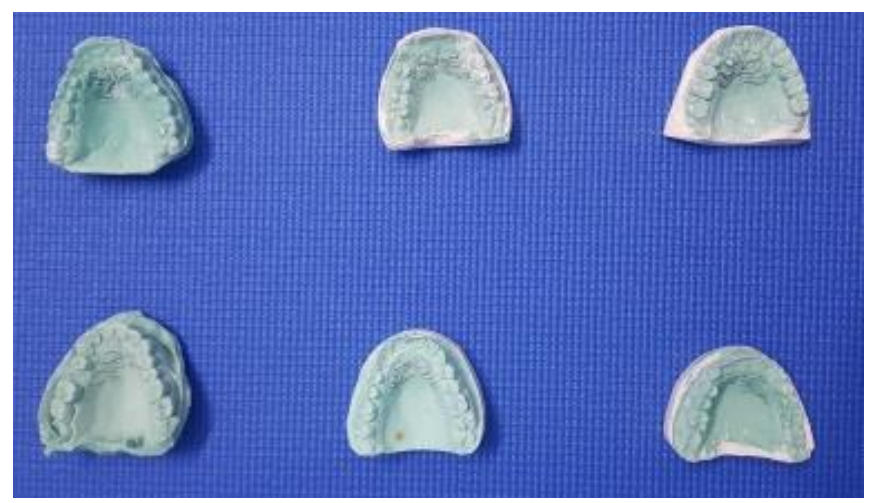

Fig 2: Image showing the tracing of different rugae pattern on the partially edentulous maxillary cast 


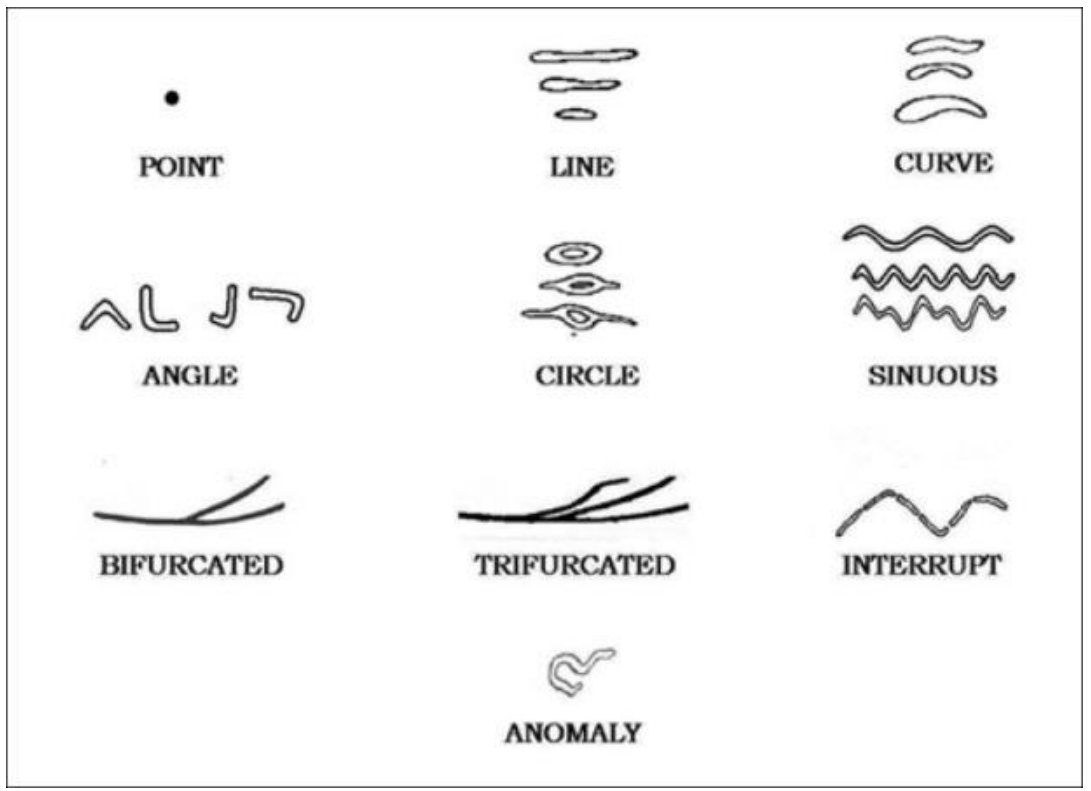

Fig 3: Image showing rugae patterns based on Martins dos Santos classification system
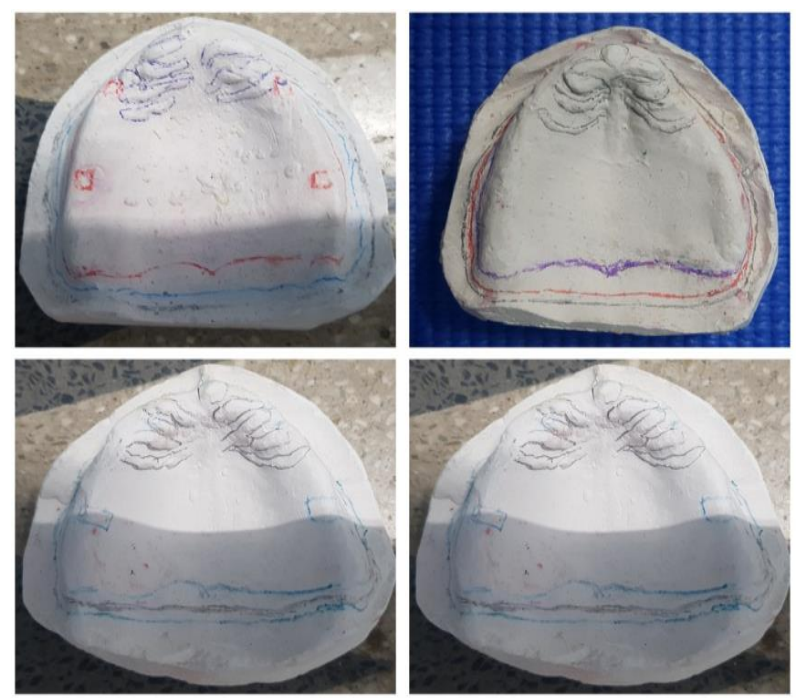

Fig 4: Image showing the tracing of different rugae pattern at 3, 6, 9 and 12 months on the completely edentulous maxillary cast
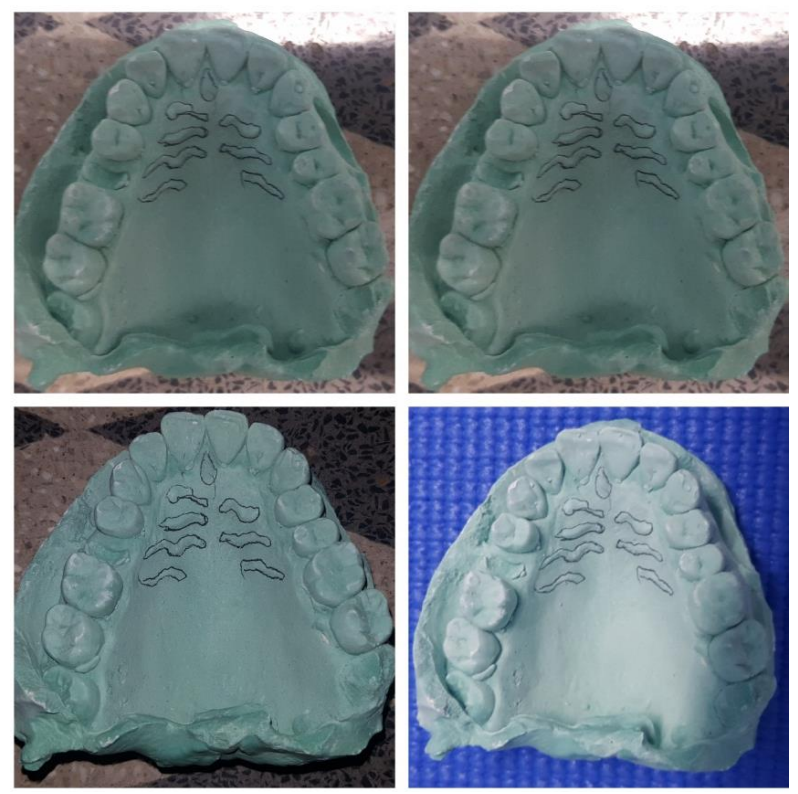

Fig 5: Image showing the tracing of different rugae pattern at 3, 6, 9 and 12 months on the partially edentulous maxillary cast

\subsection{Statistical evaluation}

The data was compiled in Microsoft excel sheet and transferred to Statistical Package for the Social Sciences (SPSS) version 19.0 for analysis. Descriptive statistics and inferential statistics were applied to evaluate the results. It was observed that the data obtained was not normally distributed thus non parametric analysis by KolmogorovSmirnova test and Shapiro-Wilk test were performed. Mean comparison between two groups based on selected parameters were evaluated using Mann-Whitney U-test and the level of significance was set at $5 \%(* \mathrm{p}<.05)$.

\section{Results}

On analysis of the given data significant differences were observed between the mean values of both the groups and also on the distribution of the rugae pattern between both the groups. Among completely edentulous individuals (group A) Sinnous pattern $(2.1 \pm 1.65)$ is more common followed by line $(1.4 \pm 1.39)$; curve $(1.4 \pm 1.48)$ and bifurcated type $(0.6 \pm$ 0.81 ) whereas in partially edentulous individuals (group B) Line pattern $(2.6 \pm 1.71)$ is more common followed by sinnous $(2.2 \pm 1.74)$; circle $(0.6 \pm 0.78)$ and bifurcated type $(0.3 \pm 0.61)$ based on number and distribution.

More complex patterns (line, curve, circle, bifurcated, sinnous) are observed in partially edentulous group (Group B) when compared to completely edentulous group (Group A) among which significant differences were observed between the mean values of line pattern ( $p$ value $=0.002 *)$, bifurcated $\left(\mathrm{p}\right.$ value $\left.=0.035^{*}\right)$ and circle pattern $\left(\mathrm{p}\right.$ value $\left.=0.001^{*}\right)(\mathrm{p}$ value $<0.05^{*}$ is considered as Statistically significant) (Table 1). Similarly on evaluation of the number and distribution of rugae pattern within the group sinnous pattern showed significant difference in the mean value over a period of 1 year among group A (completely edentulous) whereas in Group B both sinnous and line pattern showed significant differences in the mean observation values (Table 2). 
Table 1: Table showing mean comparison between groups based on rugae pattern using Mann-Whitney U-test.

\begin{tabular}{|c|c|c|c|c|c|c|}
\hline \multirow{2}{*}{ Variables } & \multicolumn{2}{|c|}{ Group A } & \multicolumn{2}{c|}{ Group B } & \multirow{2}{*}{ Z value } & \multirow{2}{*}{ p value } \\
\cline { 2 - 5 } & Mean & S. D. & Mean & S. D. & & -3.074 \\
\hline Line & 1.4 & 1.39 & 2.6 & 1.71 & $0.002^{*}$ \\
\hline Curve & 1.4 & 1.48 & 1.5 & 1.54 & -0.382 & 0.702 \\
\hline Sinnous & 2.1 & 1.65 & 2.2 & 1.74 & -0.209 & 0.834 \\
\hline Point & 0.3 & 0.69 & 0.2 & 0.43 & -0.693 & 0.488 \\
\hline Bifurcated & 0.6 & 0.81 & 0.3 & 0.61 & -2.103 & $0.035^{*}$ \\
\hline Trifurcated & 0.1 & 0.27 & 0.0 & 0.00 & -1.755 & 0.079 \\
\hline Angle & 0.3 & 0.70 & 0.2 & 0.49 & -0.382 & 0.702 \\
\hline Anomaly & 0.1 & 0.38 & 0.0 & 0.00 & -1.755 & 0.079 \\
\hline Interrupt & 0.1 & 0.32 & 0.0 & 0.00 & -1 & 0.317 \\
\hline Circle & 0.1 & 0.52 & 0.6 & 0.78 & -3.72 & $0.001^{* *}$ \\
\hline
\end{tabular}

p-value $<0.05 *$ - Statistically significant; p-value $<0.001 * *$ - Highly significant.

Table 2: Table showing non-parametric analysis performed using Kolmogorov-Smirnova test and Shapiro-Wilk test.

\begin{tabular}{|c|c|c|c|c|c|c|c|}
\hline \multicolumn{8}{|c|}{ Tests of Normality } \\
\hline \multirow[t]{2}{*}{ Group } & \multirow[t]{2}{*}{ Patterns } & \multicolumn{3}{|c|}{ Kolmogorov-Smirnova } & \multicolumn{2}{|c|}{ Shapiro-Wilk } & \multirow[b]{2}{*}{ Sig. } \\
\hline & & Statistic & df & Sig. & Statistic & $\mathrm{df}$ & \\
\hline \multirow{10}{*}{$\mathbf{A}$} & line & 0.257 & 50 & 0 & 0.844 & 50 & 0 \\
\hline & curve & 0.214 & 50 & 0 & 0.837 & 50 & 0 \\
\hline & sinnous & 0.165 & 50 & $0.009 *$ & 0.907 & 50 & $0.003 *$ \\
\hline & point & 0.48 & 50 & 0 & 0.479 & 50 & 0 \\
\hline & bifurcated & 0.324 & 50 & 0 & 0.756 & 50 & 0 \\
\hline & trifurcated & 0.535 & 50 & 0 & 0.297 & 50 & 0 \\
\hline & angle & 0.452 & 50 & 0 & 0.545 & 50 & 0 \\
\hline & anomaly & 0.529 & 50 & 0 & 0.297 & 50 & 0 \\
\hline & interrupt & 0.538 & 50 & 0 & 0.15 & 50 & 0 \\
\hline & circle & 0.52 & 50 & 0 & 0.269 & 50 & 0 \\
\hline \multirow{7}{*}{ B } & line & 0.186 & 50 & $0.002 *$ & 0.895 & 50 & $0.002 *$ \\
\hline & curve & 0.22 & 50 & 0 & 0.788 & 50 & 0 \\
\hline & sinnous & 0.17 & 50 & $0.006^{*}$ & 0.896 & 50 & $0.002 *$ \\
\hline & point & 0.511 & 50 & 0 & 0.405 & 50 & 0 \\
\hline & bifurcated & 0.461 & 50 & 0 & 0.551 & 50 & 0 \\
\hline & angle & 0.478 & 50 & 0 & 0.522 & 50 & 0 \\
\hline & circle & 0.323 & 50 & 0 & 0.75 & 50 & 0 \\
\hline
\end{tabular}

p-value $<0.05 *$ - Statistically significant;

\section{Discussion}

Difficulty in establishing the identity using hard tissue (in specifically the teeth) as a personal identification tool arises when teeth are extracted or lost due to aging process, periodontally compromised conditions, systemic diseases, extensive restorative procedures, trauma and several other factors ${ }^{[13]}$. Stability and resistance of palatal rugae is considered as a significant feature in soft tissue examination during personal identification in forensic investigation. This identification of rugae depends on several factors such as presence or absence of tooth, palatal height changes caused by degenerating alveolar bone after tooth loss, poorly delineated rugae eminences, indistinct outline or form of alveolar arches, and more complex patterns (line, curve, circle, bifurcated, sinnous) or non-complex patterns (line only) in some cases [14].

In the present study significant differences were observed between the mean values of both the groups and also on the distribution of the rugae pattern between both the groups similar to studies by Jawad IA ${ }^{[8]}$, Kapali et al. ${ }^{[15]}$, Bhatt.G [16]. Among completely edentulous individuals (group A) Sinnous pattern $(2.1 \pm 1.65)$ is more common followed by line $(1.4 \pm 1.39)$; curve $(1.4 \pm 1.48)$ and bifurcated type $(0.6 \pm$ 0.81 ) whereas in partially edentulous individuals (group B) Line pattern $(2.6 \pm 1.71)$ is more common followed by sinnous $(2.2 \pm 1.74)$; circle $(0.6 \pm 0.78)$ and bifurcated type $(0.3 \pm 0.61)$ based on number and distribution. This finding was disagreeing with the results of Jawad IA (Wavy, curved) in Iraq population ${ }^{[8]}$, Kapali et al. (Circular and straight) in Australian group ${ }^{[15]}$ and similar to result by Bhat $\mathrm{G}^{[16] \text {, }}$ Deepak et al. ${ }^{[17]}$, Poojya et al. ${ }^{[14]}$ and Rajguru et al. ${ }^{[18]}$ among Indian population. This difference in mean value of number of rugae and pattern of arrangement could be attributed to several environmental factors such as age, gender, geographical location; local factors like chewing force exerted, presence of denture as well as genetic predisposition. More complex patterns (line, curve, circle, bifurcated, sinnous) are observed in partially edentulous group (Group B) when compared to completely edentulous group (Group A) among which significant differences were observed between the mean values of line pattern $(p$ value $=0.002 *)$, bifurcated $\left(\mathrm{p}\right.$ value $\left.=0.035^{*}\right)$ and circle pattern $\left(\mathrm{p}\right.$ value $\left.=0.001^{*}\right)$. Studies by Saraf et al. ${ }^{[19]}$, Jawad IA ${ }^{[8]}$, Bhatt $\mathrm{G}^{[16]}$, Ohtani et al. ${ }^{[20]}$ and Jindal et al. ${ }^{[12]}$ also demonstrated dissimilar complex pattern and agreed with characteristic individuality, distinctiveness and genetic predisposition role in formation of the palatal rugae pattern. It was also evident that this perplexity of rugae pattern in partially edentulous individuals tends to regress in completely edentulous group.

In this study on evaluation of the number and distribution of rugae pattern within the group sinnous pattern showed significant difference in the mean value over a period of 1 year among group A (completely edentulous) whereas in Group B both sinnous and line pattern showed significant differences in the mean observation values. These observations were in contrast to studies by Bhatt $G^{[16] \text {, }}$ 
Rajguru et al. and Kapali et al. ${ }^{[15]}$. In this study duration of 1 year was preferred to clearly observe the changes caused due to uninterrupted stimulus caused by chewing mechanism in partially edentulous against completely edentulous individuals. It is well known that palatal rugae acts as a secondary stress bearing area where complex forces are acted upon continuously over a period of time. The higher significant difference in the mean value of number and type of rugae patterns in group B within the group (Partially edentulous) may be attributed to the changes occur at the lateral ends of the rugae pattern as a result of tooth movement along with physiological and functional process like chewing that takes place after loss of adjacent teeth over a period of time ${ }^{[8,9]}$. The changes were believed to be in association with the bone resorption process thus pattern of palatal rugae in completely edentulous individual group appears small, simple, non-complex, scattered with less number of patterned rugae. Nevertheless more studies on role of extent of edentulousness, pattern of tooth loss, changes associated with denture practices, and nature of alveolar ridge are needed to evaluate their significance in diverse population groups which is essential to establish palatal rugae pattern as a reliable tool in forensic identification.

\section{Conclusion}

The present study showed significant differences in the rugae pattern between both the groups signifies characteristic individuality, distinctiveness and genetic predisposition role in formation of the palatal rugae. However greater changes with complex patterns were observed in partially edentulous group when compared with the complete edentulous group could be attributed to physiological and functional process following loss of teeth that may or may not be associated with complex nature and role of duration of edentulousness and pattern of tooth loss which has to be evaluated further to ensure reliability of rugae pattern in forensic investigation.

\section{References}

1. Budowle B, Bieber FR, Eisenberg AJ. Forensic aspects of mass disasters: strategic considerations for DNA-based human identification. Legal medicine 2005;7(4):230-43.

2. Khoo L, Soon Lai P, Hafizam Hasmi A, Shah Mahmood M. Secondary identifier for positive identification in DVI. Forensic. Sci. Criminol 2016;1:1-3.

3. Krishan K, Kanchan T, Garg AK. Dental evidence in forensic identification-An overview, methodology and present status. The open dentistry journal 2015;9:250.

4. Balachander N, Babu NA, Jimson S, Priyadharsini C, Masthan KM. Evolution of forensic odontology: An overview. Journal of pharmacy \& bioallied sciences. 2015;7(Suppl 1):S176.

5. Kirchhoff S, Fischer F, Lindemaier G, Herzog $P$, Kirchhoff C, Becker $\mathrm{C}$ et al. Eisenmenger W. Is postmortem CT of the dentition adequate for correct forensic identification?: comparison of dental computed tomograpy and visual dental record. International journal of legal medicine 2008;122(6):471-9.

6. Bansode SC, Kulkarni MM. Importance of palatal rugae in individual identification. $\mathrm{J}$ Forensic Dent Sci 2009;1(2):77-81.

7. Caldasa IM, Magalhaesbed T, Afonsoa A. Establishing identity using cheiloscopy and palatoscopy. J. Forensic Sci. Int 2007; 165:1-9.

8. Jawad IA. Comparison of rugae pattern between dentate and edentulous patients in Iraqi sample. Al-Rafidain
Dental Journal 2010;10(2):265-71.

9. Avant WE. Indirect retention in partial denture design. J Prosth Dent 2003;90:1-5

10. Shetty D, Juneja A, Jain A, Khanna KS, Pruthi N, Gupta A et al. Assessment of palatal rugae pattern and their reproducibility for application in forensic analysis. Journal of forensic dental sciences 2013;5(2):106.

11. Shukla D, Chowdhry A, Bablani D, Jain P, Thapar R. Establishing the reliability of palatal rugae pattern in individual identification (following orthodontic treatment). J Forensic Odonto-Stomatol 2011;29:20-29.

12. Jindal V, Mahajan A, Mahajan N, Goel A, Kaur R, Puri C. Rugae pattern determination in periodontitis patients: A descriptive study. J Int Clin Dent Res Organ 2016;8:115-9

13. Reesu GV, Augustine J, Urs AB. Forensic considerations when dealing with incinerated human dental remains. Journal of forensic and legal medicine 2015;29:13-7.

14. Poojya R, Shruthi CS, Rajashekar VM, Kaimal A. Palatal rugae patterns in edentulous cases, are they a reliable forensic marker?. International journal of biomedical science: IJBS 2015;11(3):109.

15. Kapali S, Townsend G, Richards L, Parish T. Palatal rugae patterns in Australian Aborigines and Caucasians. Austr Dent J . 1997;42:129-133.

16. Bhatt G. Comparison of Rugae Pattern between Dentulous and Edentulous Population of Rajasthan State. J Forensic Res 2015;6:1-3.

17. Deepak V, Malgaonkar NI, Shah NK, Nasser AS, Dagrus $\mathrm{K}$, Bassle T. Palatal rugae patterns in orthodontically treated cases, are they a reliable forensic marker? J Int Oral Health 2014;6(5):89-95.

18. Rajguru JP, Misra SR, Somayaji NS, Masthan KM, Babu AN, Mohanty N. A comparative rugoscopic study of the dentate and edentulous individuals in the South Indian population. The Scientific World Journal 2014.

19. Saraf A, Bedia S, Indurkar A. Rugae patterns as an adjunct to sex differentiation in forensic identification. J. Forensic Odontostomatol 2011;29:14-19.

20. Ohtani M, Nishida N, Chiba T, Fukuda M, Migamoto Y, Yoshioka N. Indication and limitation of using palatal rugae for personal identification in edentulous cases. Forensic Sci Int 2008;176:178-182. 